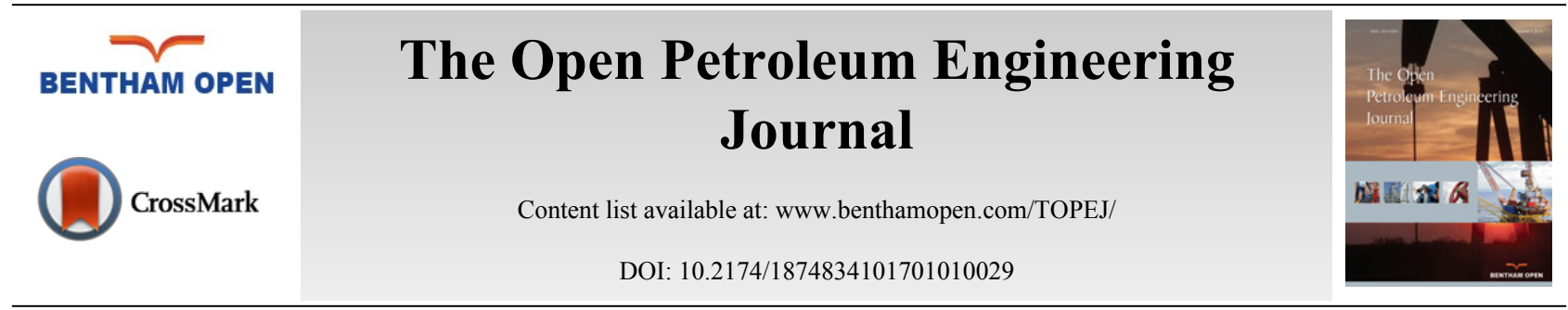

RESEARCH ARTICLE

\title{
Block Selection Mode of the Fire Flooding Based on Influence Factors Analysis
}

\author{
Yuan Shi-bao ${ }^{1, *}$, Jiang Hai-yan ${ }^{1}$, Wang Boyi ${ }^{1}$ and Li Qing-qing ${ }^{2}$ \\ ${ }^{\prime} X i$ 'an Shiyou University, Xi'an 710065, P. R. China \\ ${ }^{2}$ China University of Petroleum, Qing Dao 266555, P. R. China
}

Received: April 27, 2016

Revised: January 06, 2017

Accepted: January 16, 2017

\begin{abstract}
:
Background:

In-situ combustion is a complex process with multi-factors, like geology, development and engineering. All of the factors can affect the ultimate effect of in-situ combustion.
\end{abstract}

\section{Objective:}

Strengthen the research of candidate reservoir screening method and mode for fire flooding.

\section{Method:}

On the basis of summarizing formers' single factor screening conditions, and according to the strength degree of the influence factors on geology and development. The candidate reservoirs are divided into three types for screening, first, second and not suitable. Then the in-situ combustion process is taken as a grey system on the analysis of the influence factors. The fire flooding evaluation model is established using the method of correlation analysis that selects the main factors.

\section{Results:}

Block selection mode of fire flooding is established and using an example to calculate and evaluate the applicability.

\section{Conclusion:}

This fire flooding reservoir screening model breaks through the traditional single index screening model, and selects out suitable reservoirs for fire flooding, which improved the test success rate. The J function is convenient to calculate the fire flooding effect, and accurately guide the in-situ combustion experimental blocks screening and in-situ combustion project evaluation.

Keywords: Uncertainty, Multi-factors, Correlation analysis, Grey system, Fire flooding, Porosity.

\section{INTRODUCTION}

Fire flooding (in-situ combustion) is a kind of thermal recovery technology, and since the advent of more than 50 years, a set of related technology has gradually emerged about fire flooding method [1], screening criteria [2, 3], and effects prediction [4]. In recent years, the fire flooding mainly is regarded as a replacement development means in heavy oil reservoirs at the later stage after steam injection in China. But only a part of fire flooding field tests was effective [1]. Because the basic geological conditions of some reservoirs had an adverse effect on fire flooding. So it is necessary to strengthen the research of candidate reservoir screening method and mode for fire flooding. Influence

\footnotetext{
* Address correspondence to this author at the Xi'an Shiyou University, Xi'an, Shaanxi Province, 710065, P. R. China; Tel: +86 15339145717; E-mails: upcysb@126.com, sbyuan@xsyu.edu.cn
} 
factors of fire flooding is studied by using the method of statistical analysis and grey correlation. Then established the selection pattern of fire flooding blocks and feasibility evaluation functions, which provided basis for fire flooding block selection, scheme evaluation and effect prediction.

\section{MAIN FACTORS INFLUENCING THE FIRE FLOODING EFFECT}

\subsection{Analysis of Factors Influencing the Fire Flooding Effect}

There are many influence factors about fire flooding to be considered. They can be summarized in three aspects as follows: reservoir geological conditions, reservoir development conditions and engineering. These three aspects cover almost all influence factors of fire flooding. Most of them are not controllable and some need to be adjusted and reformed. All of them can impact the effect of fire flooding more or less.

Reservoir geological factors are uncontrollable factors in the fire flooding process, which need to be overcome by strict screening criteria. Generally, the reservoir screening quantitative geological factors of fire flooding need to be considered are buried depth, thickness, dip, permeability, and fluid properties, etc.

In heavy oil reservoirs at a later stage of steam stimulation, long time of steam stimulation will lead to the change of reservoir parameters, so it is necessary to discuss the effect of reservoir development on fire flooding. Reservoir pressure, oil saturation and formation temperature can beused to characterize the reservoir development status after steam stimulation or other recovery methods $[5,6]$. Lower reservoir pressure is beneficial for fire flooding. After years of steam flooding, a large amount of thermal energy has been added to the formation and the water saturation has increased at the same time.

Operation process of fire flooding mainly through the mediation of fire flooding engineering parameters [7] to realize the control of the underground combustion, air injection rate, water/gas ratio and injector to producer well ratio are the main operation parameters of conventional fire flooding.

\subsection{Correlation Analysis of Influence Factors by the Grey Theory}

Correlation analysis is the significant content in the grey theory created by professor Deng Julong [8], is a kind of uncertain analysis method, the essence of which is convey the diffidence among the geometry of the curve, based on the difference size to determine the degree of close [9]. Various influence factors in the process of fire flooding have different degrees on effect and the relationship between the factors are not entirely clear. So it can be regarded as an information incomplete system, namely grey system.

From the published literature $[2,10,11]$, collected 34 cases of fire flooding both at home and abroad, including primary development, fire flooding development after steam stimulation, dry and wet fire flooding, and relevant parameters involved in three categories of geology, exploitation and engineering, and it can sum up to 14 items, the sample has universality and representativeness.

In the grey system of fire flooding, the relationship between a variety of factors (comparison array) and fire flooding effect (reference array) need to be determined ultimately, there are many factors affecting the fire flooding effect, through the analysis, buried depth $(Z)$, thickness $(\mathrm{h})$, dip $(\theta)$, porosity $(\phi)$ and permeability $(\mathrm{K})$, reservoir temperature $(T)$, reservoir pressure $\left(\mathrm{P}_{\mathrm{r}}\right)$, oil saturation $\left(\mathrm{S}_{\mathrm{o}}\right)$, crude oil density $(\mathrm{D})$, crude oil viscosity $(\mu)$, mobility $(\mathrm{Kh} / \mu)$, gas injection velocity $(\mathrm{v})$, water/gas ratio (WOR) and storability $\left(\phi \mathrm{S}_{\mathrm{o}}\right)$, a total of 14 representative factors are selected as comparison sequence. Air/oil ratio $\left(\mathrm{m}^{3} / \mathrm{m}^{3}\right)$ which represents the fire flooding effect is taken as reference sequence of grey relation analysis.

According to close degree obtained from sample data, influence factors are classified, and the results are shown in Table 1. Analyze factors of different classes, and then screen out main factors, which are taken as key consideration in the next step of block selection and engineering operation process.

Table 1. Degree of association, close contrast ratio and evaluation of compare sequence and reference sequence.

\begin{tabular}{|c|c|c|c|}
\hline Influence factors & Degree of association $r_{o i}$ & Association level $\beta_{o i}$ & Sequencing \\
\hline Buried depth & 0.462 & 0.893 & 7 \\
\hline Thickness & 0.421 & 0.812 & 10 \\
\hline Dip & 0.404 & 0.781 & 13 \\
\hline
\end{tabular}


(Table 1) contd....

\begin{tabular}{|c|c|c|}
\hline Influence factors & Degree of association $\boldsymbol{r}_{\boldsymbol{o} i}$ & Association level $\boldsymbol{\beta}_{\boldsymbol{o}}$ \\
\hline Porosity & 0.505 & 0.976 \\
\hline Permeability & 0.509 & 0.983 \\
\hline Mobility & 0.510 & 0.985 \\
\hline Storability & 0.483 & 0.932 \\
\hline Reservoir temperature & 0.452 & 0.872 \\
\hline Reservoir pressure & 0.415 & 0.801 \\
\hline Oil saturation & 0.495 & 0.955 \\
\hline Crude oil density & 0.406 & 0.784 \\
\hline Crude oil viscosity & 0.456 & 11 \\
\hline Average gas injection rate & 5 & 12 \\
\hline Water/gas ratio & 0.518 & 0.880 \\
\hline
\end{tabular}

According to the results of correlation analysis, select close and close level parameters as main influence factors of in-situ combustion. The geological influence factors of in-situ combustion include depth, mobility, permeability, porosity and oil saturation; developing factors mainly consist of reservoir temperature and storability; engineering factor is mainly the average gas injection rate.

The above discussions are based on the analysis conclusion of influence factors, and all analysis is for single factor that lack of a lateral comprehensive comparison of various factors. For a specific reservoir, the final fire flooding effect will be decided by one or a combination of several factors, so it is necessary to establish a fire flooding block selection mode based on the level of influence factors.

\section{FIRE FLOODING BLOCK SELECTION MODE}

\subsection{Reservoir Type Selection}

According to characteristics of heavy oil reservoir, we classify the list heavy oil reservoirs, the block diagram which is suitable for the in-situ combustion is shown in Fig. (1), and it was divided into three types, preferred reservoir, second reservoir, unsuitable reservoir.

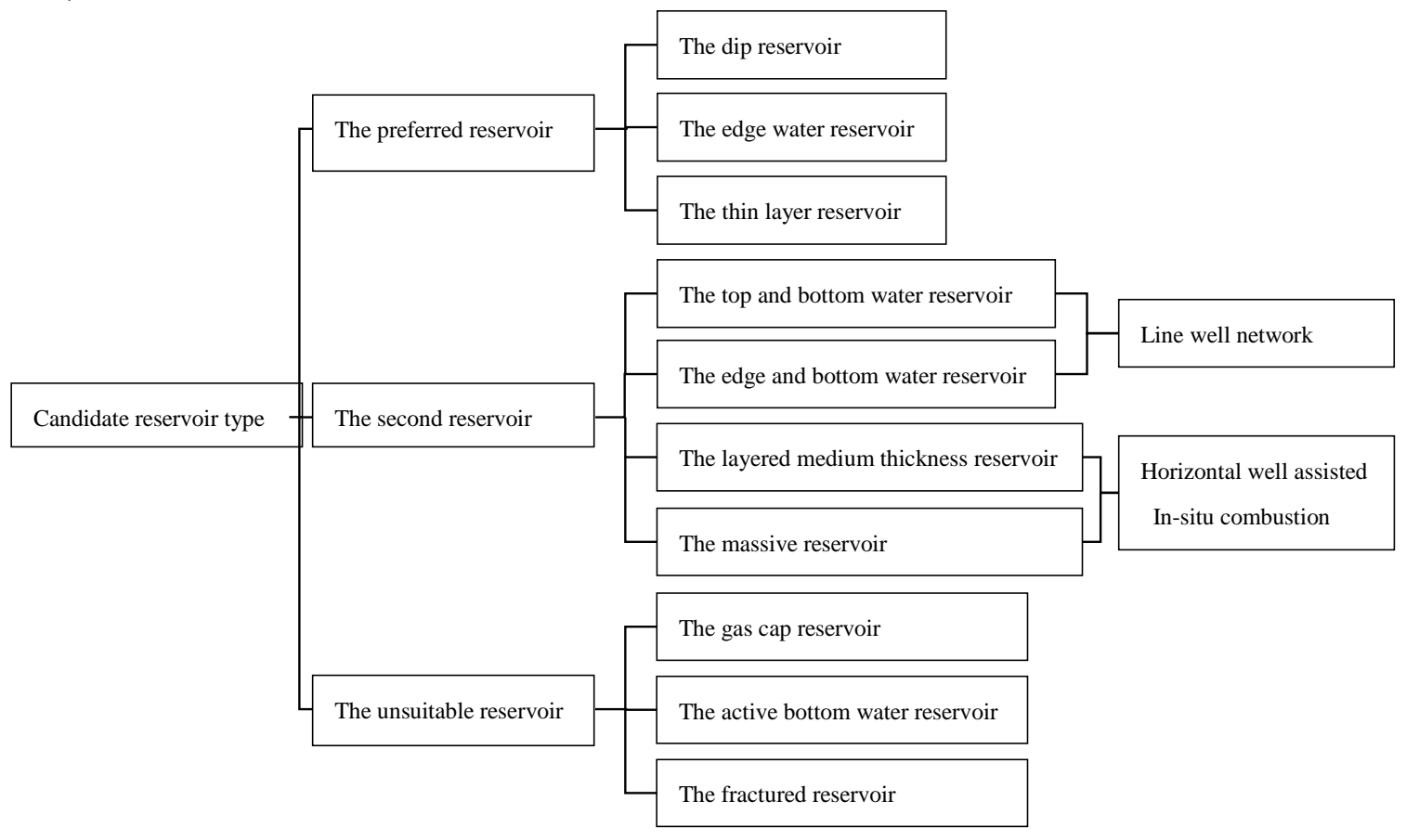

Fig. (1). Screening reservoir type diagram.

The preferred reservoir types include the dip reservoir, the edge water reservoir and thin layer reservoir. Structure dip is the most important factor for combustion wells location selection, and the migration rate of gas injection and 
combustion front is faster in updip direction than downdip, so gas injectors are usually located in the structure of high position. Moderate reservoir thickness can avoid gas overlap and excessive gas heat loss of top and bottom, generally between 1.5 and $15 \mathrm{~m}$. The only requirement for permeability is that air can be injected to the formation under the pressure of cap rock condition allowing, and the minimum requirement for oil property is the mobility in the underground.

The second reservoir include top and bottom water reservoir, edge and bottom water reservoir, the layered oil reservoir of medium thickness and the massive reservoir. For the second reservoir, risk will increase in the process of in-situ combustion, but successful examples [12 - 17] at home and abroad are still existed. Massive thick and layer thick reservoirs can improve the development effect in horizontal well by in-situ combustion, which should be considered in the economic evaluation. Top and bottom water reservoir as well as edge and bottom water reservoir must use determinant well pattern. The screening criteria should be improved for the next round of screening of the second reservoir.

The inappropriate reservoirs for in-situ combustion mainly are those with gas cap, active bottom water and fractures, and successful examples at home and abroad are very few, even field operation is very difficult and those are not recommended as candidate reservoir blocks.

\subsection{Reservoir Development History Selection}

In-situ combustion can be applied to natural extraction and steam stimulation. And strong waterflooding reservoirs are unsuitable for in-situ combustion, but if just a short period of time, in-situ combustion can go on. Details are shown in Fig. (2).

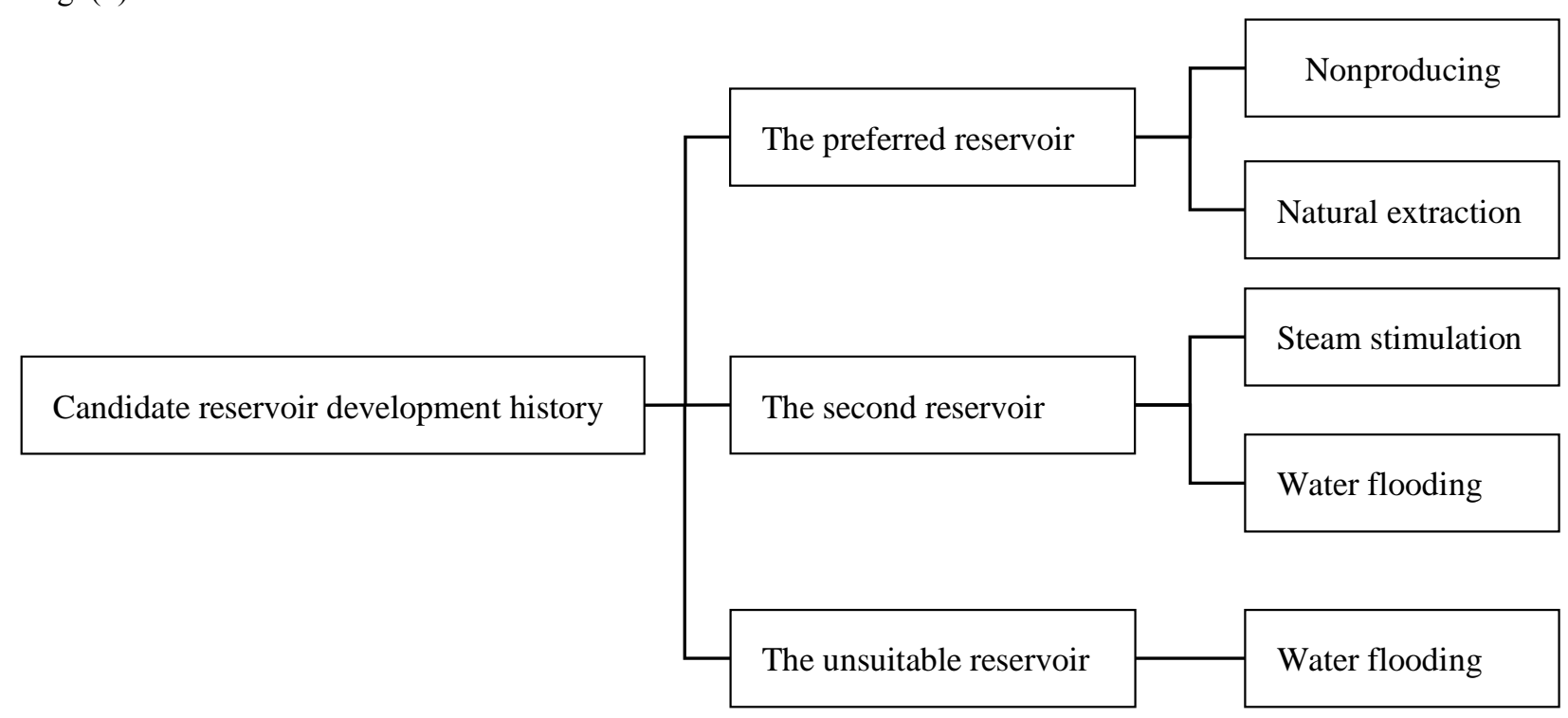

Fig. (2). In-situ combustion adaptability analysis diagram of reservoir development history.

\subsection{Candidate Reservoir Parameters Range Selection}

Steps of screening block according to the reservoir and fluid parameters are follows;

1. Fuel Content: The fuel content of the candidate reservoir should be within the scope of $13 \sim 45 \mathrm{~kg} / \mathrm{m}^{3}$.

2. Reservoir Connectivity: Reservoir has good lateral connectivity, namely the objective layer is relatively stable in work area, lithofacies and petrophysics change little.

3. Reservoir Heterogeneity: There are no thief zones in vertical, permeability variation coefficient is less than 0.75 .

4. Reservoir and Fluid Physical Properties: The properties can be compared obtained based on successful examples of in-situ combustion at home and abroad, also can refer to data from Table 1, which is on the basis of formers' research results. According to the actual production and Support Vector Machine (SVM) [4] to establish the preferred and second reservoir model, then calculate the reservoir screening parameters in Table 2. 
Table 2. Reservoir parameters suitable for in-situ combustion development.

\begin{tabular}{|c|c|c|c|c|}
\hline \multicolumn{2}{|c|}{ Optional reservoir } & \multirow{2}{*}{\begin{tabular}{|c|} 
Main parameter index of oil reservoir \\
\\
Porosity $\geq 0.18$ \\
Initial oil saturation $\geq 0.35$ \\
$3 \mathrm{~m}<$ effective net sand $<20 \mathrm{~m}$ \\
Formation temperature degassed oil \\
Viscosity $\leq 8000 \mathrm{mPa} \cdot \mathrm{s}$
\end{tabular}} & \multirow[b]{2}{*}{$\begin{array}{c}\text { Reservoir auxiliary index } \\
\text { Net aggregate thickness } \\
\text { ratio } \\
>0.5 \\
\text { Permeability } \\
>100 \times 10^{-3} \mu \mathrm{m}^{2}\end{array}$} & \multirow{2}{*}{$\begin{array}{c}\begin{array}{c}\text { Remarks (selecting } \text { in-situ } \\
\text { combustion) }\end{array} \\
\\
\text { Largest feasibility }\end{array}$} \\
\hline $\begin{array}{l}\text { Preferred } \\
\text { reservoir }\end{array}$ & $\begin{array}{c}\text { Reservoir type: } \\
\text { Dip reservoir; } \\
\text { Edge water reservoir; } \\
\text { Thin Layer reservoir } \\
\text { Reservoir development } \\
\text { history: } \\
\text { Nonproducing time; } \\
\text { Natural producing time }\end{array}$ & & & \\
\hline \multirow[t]{2}{*}{$\begin{array}{l}\text { Second } \\
\text { reservoir }\end{array}$} & $\begin{array}{c}\text { Reservoir type: } \\
\text { Underscreen and bottom } \\
\text { water reservoir; } \\
\text { Edge and bottom water } \\
\text { reservoir } \\
\text { Reservoir development } \\
\text { history: } \\
\text { After steam stimulation; } \\
\text { After water flooding }\end{array}$ & $\begin{array}{c}\text { Porosity } \geq 0.22 \\
\text { Initial oil saturation } \geq 0.43 \\
\text { Effective net sand } \geq 3 \mathrm{~m} \\
\text { Formation temperature degassed oil } \\
\text { Viscosity } \leq 5000 \mathrm{mPa} \cdot \mathrm{s}\end{array}$ & $\begin{array}{l}\text { Net aggregate thickness } \\
\text { ratio } \\
>0.6 \\
\text { Permeability } \\
>200 \times 10^{-3} \mu \mathrm{m}^{2}\end{array}$ & $\begin{array}{l}\text { Line well network should be } \\
\text { taken }\end{array}$ \\
\hline & $\begin{array}{l}\text { Layered medium thickness } \\
\text { oil reservoir; } \\
\text { Massive oil pool }\end{array}$ & $\begin{array}{c}\text { Porosity } \geq 0.20 \\
\text { Initial oil saturation } \geq 0.38 \\
\text { Effective net sand } \geq 3 \mathrm{~m} \\
\text { Formation temperature degassed oil } \\
\text { Viscosity } \leq 7000 \mathrm{mPa} \cdot \mathrm{s}\end{array}$ & $\begin{array}{l}\text { Net aggregate thickness } \\
\text { ratio } \\
>0.5 \\
\text { Permeability } \\
>150 \times 10^{-3} \mu^{2}\end{array}$ & $\begin{array}{c}\text { Horizontal well technology to in- } \\
\text { situ com bustionfield test must } \\
\text { be conducted }\end{array}$ \\
\hline
\end{tabular}

In order to reflect the interaction effects between various factors and the comprehensive effect, Chu [10] in 1977, researched the regression function of $\mathrm{Y}, \mathrm{Y}$ is a function of reservoir buried depth, porosity, permeability, initial oil saturation and oil viscosity. Because $\mathrm{Y}$ function is convenient and the result of calculation is reliable. So it is often taken as a necessary reference in fire flooding reservoir screening. But $\mathrm{Y}$ function does not consider the engineering factors. There will be differences from the actual situations. Therefore, a new function is proposed. In order to distinguish it from Y function, it is called $\mathbf{J}$ function in this function regression. According to the correlation analysis, reservoir temperature and injection rate are added to the regression independent variable as close parameters, $\mathrm{J}$ is multivariable linear function of reservoir buried depth, temperature, permeability, mobility, gas injection rate and coefficient of storage .

Giving regression analysis of $\mathbf{J}$ function using Marquardt method of Matlab software, and $\mathbf{J}$ value is defined as follows: (1) $\mathrm{J}=1$, scheme is feasible in technology and economy; (2) $\mathrm{J}=0$, technically feasible, economically may fail; (3) $\mathrm{J}=-1$, completely infeasible. The final equation is as following:

$$
\begin{aligned}
J=-1.616698 & +0.000477 Z+0.0147029 T+9.843 \times 10^{-5} K \\
& +9.638 \times 10^{-5} \mathrm{Kh} / \mu-1.11 \times 10^{-6} V+8.86 \phi S_{o}
\end{aligned}
$$

Where,

\section{Z-Reservoir Buried Depth, m;}

T-Reservoir Temperature, ${ }^{\circ} \mathrm{C}$;

K-Average Reservoir Permeability, $10^{-3} \mathrm{\mu m}^{2}$;

h-Reservoir Thickness, m;

$\mu$-Viscosity of Crude Oil, mPa.s;

$\mathrm{v}$-Average Gas Injection Rate, $\times 10^{3} \mathrm{~m}^{3} / \mathrm{d} ;$

$\phi$-Reservoir Porosity, Decimal;

\section{So-Oil Saturation, $\%$;}

By simulation, multiple correlation coefficient of the formula is 0.9231 . When using function J, selected parameters are plugged into the function $J$ to calculate firstly, and screened fire flooding blocks according the $J$ value, then analyzed rationality of fire flooding parameters, and finally evaluated fire flooding effect. Successful projects of 
statistical technique and economy, calculated the value of $\mathrm{J}$ is between $0.3 \sim 1.5$. For $\mathrm{J}$ value that less than 0.3 is not successful or unsuccessful project economically, and the bigger value of $\mathrm{J}$ is more close to economic success as a whole.

\section{EXAMPLES ANALYSIS}

According to the reservoir parameters from successful fire flooding oilfields, screened out suitable parameters from six blocks (M5, D66, D48, W82, J35, CT) in Liaohe oilfield. Geological conditions of D66, D48 and M5 blocks shown in Table 3 are similar to the oil reservoir parameters of foreign successful fire flooding.

Table 3. Geological parameters of six blocks.

\begin{tabular}{|c|c|c|c|c|c|c|}
\hline Block & D66 & D48 & M5 & $\mathbf{J 3 5}$ & W82 & CT \\
\hline Reservoir type & $\begin{array}{c}\text { Thin interbed, } \\
\text { heavy oil }\end{array}$ & $\begin{array}{c}\text { Thin interbed, } \\
\text { heavy oil }\end{array}$ & $\begin{array}{l}\text { Medium porosity, } \\
\text { Extra low } \\
\text { permeability, thin } \\
\text { layer, heavy oil }\end{array}$ & $\begin{array}{c}\text { Multi oil group, } \\
\text { thick interbed }\end{array}$ & $\begin{array}{l}\text { Medium to thick } \\
\text { layers, heavy oil }\end{array}$ & $\begin{array}{l}\text { Micro fracture, } \\
\text { mixed rock block, } \\
\text { bottom water } \\
\text { reservoir }\end{array}$ \\
\hline Crude oil reserves, $10^{4} \mathrm{t}$ & 1551 & 1689 & 213 & 465 & 553 & 765 \\
\hline Depth (average), $\mathrm{m}$ & 1050 & 1100 & 550 & 1380 & 1310 & 1300 \\
\hline Dip angle, ${ }^{\circ}$ & $<8$ & 10 & 11 & 12 & 22 & \\
\hline Permeability, md & 781 & 918 & 13 & 644 & 709 & 36 \\
\hline Thickness,m & 42 & 27 & 18 & $24 / 21$ & $45-60$ & 51 \\
\hline Porosity, $\%$ & 25 & 28 & 23 & 20 & 30.7 & 7.3 \\
\hline Viscosity,cp & $300 / 2000$ & $500 / 10000$ & 111 & $90 / 294$ & 6500 & 31 \\
\hline Oil saturation, $\%$ & 65 & 60 & 65 & 65 & 62.7 & 55 \\
\hline Recovery ratio, $\%$ & 20 & 14 & 3 & 12 & & \\
\hline Current pressure, $\mathrm{MPa}$ & 1.05 & 1.5 & 5.3 & 5 & $12-16$ & \\
\hline Well spacing,m & $70 / 100$ & 100 & 141 & 150 & 100 & \\
\hline Formation type & Sandstone & Sandstone & Sandstone & Sandstone & Sandstone & Metamorphic rock \\
\hline Development history & $\begin{array}{l}\text { Steam stimulation } \\
\quad(1986 \sim 2005)\end{array}$ & \begin{tabular}{|c|} 
Steam stimulation \\
(Since 1987)
\end{tabular} & $\begin{array}{l}\text { Steam stimulation } \\
\quad(1993 \sim 2005)\end{array}$ & $\begin{array}{c}\text { Water flooding } \\
\text { (Since 1996) }\end{array}$ & $\begin{array}{l}\text { Steam stimulation } \\
\quad(1992 \sim 2007)\end{array}$ & $\begin{array}{l}\text { Steam stimulation } \\
\quad \text { (Since 2003) }\end{array}$ \\
\hline
\end{tabular}

\subsection{Step 1: Prefer the Candidate Reservoir Type}

In terms of reservoir types, D66, D48, M5 blocks with extra-low permeability and thin heavy oil reservoirs, J35, W82 medium-thick alternating layers heavy oil reservoirs are suitable for in-situ combustion, while micro-fracture and bottom water of CT reservoirs are not conducive to conduct in-situ reservoir combustion, however, as long as the crack growth is not strong, bottom water is inactive, it also can conduct in-situ combustion, and only better conditions of other factors can make sure the success of in-situ combustion. When the optional blocks structure exist high permeability channel, many reservoir fractures and large gas caps, they are not applicable for in-situ combustion, so filtered out directly and not entering the next round of screening.

In terms of reservoir types, applicability of the optional six in-situ combustion reservoirs from strong to weak order is: D66 and D48, M5, J35 and W82, CT.

\subsection{Step 2: Adaptability Analysis of Reservoir Development History}

Reservoir development history of each block are shown in Table 3. Reservoir development history of optional block mainly includes steam stimulation and waterflooding. From the research, reservoirs after steam stimulation or waterflooding are feasible for in-situ combustion, and the shorter production history, the better the effect of in-situ combustion. However the risk of in-situ combustion will increase in reservoirs after strong water flooding.

\subsection{Step 3: Candidate Reservoir Parameters Boundary Selection}

According to reservoir parameters of successful fire flooding reservoirs, the six blocks M5, D66, D48, W82, J35 were screened. And D66, D48 and M5 blocks are selected because their parameters mainly within the reservoir parameters of fire flooding succeed.

\subsection{Step 4: Oil Recovery Effect Prediction in Candidate Reservoirs of In-situ Combustion}

By using the $\mathrm{J}$ function to calculate the screening parameters of these three blocks, the results are in Table $\mathbf{4}$ and the 
$\mathrm{J}$ value of D48 block is 0.92 . It means that fire flooding is more likely to succeed in this block and this is consistent with the results of support vector machine(SVM) method [18]. So, D48 block is chosen as the preferred block for in-situ combustion.

Table 4. Function calculation results.

\begin{tabular}{|c|c|c|}
\hline Blocks & Air/ oil $\mathbf{r a t e}\left(\mathbf{m}^{\mathbf{3}} / \mathbf{m}^{\mathbf{3}}\right)$ & $\mathbf{J} \mathbf{v a l u e}$ \\
\hline D66 & 1968 & 0.81 \\
\hline D48 & 2360 & 0.92 \\
\hline M5 & 3376 & 0.51 \\
\hline
\end{tabular}

\section{CONCLUSION}

Fire flooding reservoir screening model was established in accordance with the fire flooding affecting factors divided into reservoir types, development history, and reservoir parameters which are used for effect prediction. It broke through the traditional single index screening model, and could select out suitable reservoirs for fire flooding, which improved the test success rate.

Fire flooding process is a complex gray system depending on many factors, the return of the $\mathrm{J}$ function process takes the engineering technical parameters and the late reservoir development factors into consideration, such as temperature, and it is convenient to calculate the fire flooding effect, and accurately guide the in-situ combustion experimental blocks screening and in-situ combustion project evaluation.

\section{CONFLICT OF INTEREST}

We declare that we do not have any commercial or associative interest that represents a conflict of interest in connection with the work submitted.

\section{ACKNOWLEDGEMENTS}

Thanks for the Project supported by the National Natural Science Foundation of China (No. 51674198), Scientific Research Projects of Education Department of Shaanxi Provincial Government (No. 16JS095), and Natural Science Foundation of Shaanxi Province (No.2016JM5031).

\section{REFERENCES}

[1] Z.H. Jing-hua, and W.A. Shuanghu, In-situ Combustion Oil Recovery, Petroleum Industry Press: Beijing, 2000, pp. 11-28.

[2] W.A. Mi-kang, and Z.H. Yi, In-situ Combustion Thermal Recovery, University of Petroleum Press: Beijing, 1998 , pp. $123-167$.

[3] Z.H. Ru, Heavy Oil Thermal Recovery Technology, Petroleum Industry Press: Beijing, 1999, pp. 521-523.

[4] Y.U. Shi-bao, and J.I. Hai-yan, "Effect prediction of in-situ combustion based on Support Vector Machine", Petrol. Explor. Dev., vol. 27, no. 1, pp. 69-71, 2007.

[5] L.I. Qingyuan, "Analysis on adaptability of production by in situ combustion process in heavy oil reservoir in well block hongqian-1, karamay oilfield", Xinjiang Pet. Geol., vol. 35, no. 3, pp. 333-336, 2014.

[6] W. Guan, and S. Wang, "Analysis for difference between laboratory experiment results and analytical model solution of in-situ combustion in Zheng 408 block", Pet. Geol. Recov. Effic., vol. 13, no. 1, pp. 87-89, 2006.

[7] J. Yao, and F.A. Du Dian, "Effect of development parameters on in-situ combustion after injecting steam in LEAN oilfield", J. China Univ. Pet. Ed. Nat. Sci., vol. 13, no. 1, pp. 87-89, 2003.

[8] Z.H. Ming-chen, and C.H. Yue-ming, "Influencing factors uncertainty of profile control and gray association analysis", J. China Univ. Pet. Ed. Nat. Sci., vol. 30, no. 6, pp. 59-60, 2006.

[9] Y.I. De-sheng, and G.U. Ping, Grey Theory and Method, Petroleum Industry Press: Beijing, 1992, pp. 25-33.

[10] C. Chu, "A study of fireflood field projects (includes associated paper 6504)", J. Pet. Technol., vol. 29, pp. 111-120, 1977. [http://dx.doi.org/10.2118/5821-PA]

[11] C. Cheih, "State-of-the-art review of fireflood field projects", J. Pet. Technol., vol. 34, pp. 19-32, 1982. [http://dx.doi.org/10.2118/9772-PA]

[12] C.F. Gates, K.D. Jung, and R.A. Surface, "In-situ combustion in the tulare formation, south belridge field, kern county, california", J. Pet. Technol., vol. 30, pp. 65-54, 1978.

[http://dx.doi.org/10.2118/6554-PA]

[13] M. Greaves, and M. Al-Honi, "Three-dimensional studies of in-situ combustion-horizontal wells process with reservoir heterogeneities", $J$. Can. Pet. Technol., vol. 39, pp. 25-32, 2000. 
[http://dx.doi.org/10.2118/00-10-01]

[14] H. Liu, "Feasibility study of formation combustion of Henan shallow layer heavy oil oilfield", Pet. Geol. Eng., vol. 25, no. 3, pp. 79-84, 2011.

[15] W.E. Showalter, and A.M. Maclean, "Fireflood at brea-olinda field, orange county, California", In: SPE Improved Oil Recovery Symposium, 1974, pp. 47-63.

[http://dx.doi.org/10.2118/4763-MS]

[16] L.F. Elkins, D. Morton, and W.A. Blackwell, "Experimental fireflood in a very viscous oil-unconsolidated sand reservoir, S.E. Pauls Valley Field, Oklahoma", In: Fall Meeting of the Society of Petroleum Engineers of AIME, San Antonio, Texas, 1972, pp. 79-86. [http://dx.doi.org/10.2118/4086-MS]

[17] C.F. Gates, and I. Sklar, "Combustion as a primary recovery process-midway sunset field", J. Pet. Technol., vol. 23, pp. 30-54, 1971. [http://dx.doi.org/10.2118/3054-PA]

[18] S. Yuan, and H. Jiang, "Effect prediction of in-situ combustion based on support vector machine", Petrol. Explor. Dev., vol. 34, no. 14, pp. 104-107, 2007.

(C) 2017 Shi-bao et al.

This is an open access article distributed under the terms of the Creative Commons Attribution 4.0 International Public License (CC-BY 4.0), a copy of which is available at: https://creativecommons.org/licenses/by/4.0/legalcode. This license permits unrestricted use, distribution, and reproduction in any medium, provided the original author and source are credited. 